\title{
Job Burnout and Occupational Stressors among Chinese Healthcare Professionals at County-Level Health Alliances
}

\author{
Yan Liu ${ }^{1,2}, \mathrm{Li} \mathrm{Lu}^{3, * \mathbb{C}}$, Wen-Xin Wang ${ }^{1}$, Shou Liu ${ }^{1,2}$, Hong-Ru Chen ${ }^{1,2}$, Xiang Gao ${ }^{2}$, \\ Ming-Yu Huang ${ }^{2}$, Yong-Nian Liu ${ }^{2}$, Yan-Ming Ren ${ }^{2}$ and Chao-Cai Wang ${ }^{4, *}$ \\ 1 Department of Public Health, Medical College of Qinghai University, Xining 810001, Qinghai, China; \\ qhyxyly@aliyun.com (Y.L.); xin313amazing@163.com (W.-X.W.); liushou2004@aliyun.com (S.L.); \\ hongru823@163.com (H.-R.C.) \\ 2 Health Development Research Center, Medical College of Qinghai University, Xining 810001, Qinghai, \\ China; gaoxiang@qhu.edu.cn (X.G.); qyhuangmingyu@126.com (M-Y.H.); liuyongnian@qhu.edu.cn (Y.-N.L.); \\ btyqh@126.com (Y.-M.R.) \\ 3 Team IETO, Bordeaux Population Health Research Center, UMR U1219, INSERM, Université de Bordeaux, \\ 33076 Bordeaux, France \\ 4 Department of Infection Disease, Qinghai Center for Disease Prevention and Control, Xining 810001, \\ Qinghai, China \\ * Correspondence: liser@outlook.com or li.lu@u-bordeaux.fr (L.L.); qhcdcwzc@126.com (C.-C.W.)
}

Received: 24 February 2020; Accepted: 11 March 2020; Published: 12 March 2020

\begin{abstract}
Background: This study aimed to examine the degrees of job burnout and occupational stressors and their associations among healthcare professionals from county-level health alliances in Qinghai-Tibet Plateau, China. Methods: A cross-sectional study was conducted in county-level health alliances in Qinghai Province, China, in November 2018. The Maslach Burnout Inventory-General Survey and the 38-item Chinese version of the "Scale for occupational stressors on clinicians" were used. Medical staff in four health alliances from two counties were invited to complete the questionnaire. Results: A total of 1052 (age: $34.06 \pm 9.22$ years, $79.1 \%$ females) healthcare professionals were included, $68.2 \%$ (95\% CI: 65.2-71.0\%) of the participants had job burnout symptoms. Occupational stressors had positive associations with moderate (OR $=1.06,95 \% \mathrm{CI}: 1.05-1.07)$ and serious (OR $=1.15$, 95\% CI: 1.13-1.19) level of job burnout. Stressors from vocational interest produced the greatest magnitude of odds ratio (OR $=1.76,95 \%$ CI: 1.62-1.92) for serious degree of burnout, followed by doctor-patient relationship, interpersonal relationship as well as other domains of occupational stressors. Conclusions: Job burnout was very common among healthcare professionals working in Chinese county-level health alliances, different occupational stressors had associations with job burnout. Appropriate and effective policies and measures should be developed and implemented.
\end{abstract}

Keywords: job burnout; occupational stressors; healthcare professional; county-level health alliance; plateau area; China

\section{Introduction}

Job burnout is a common syndrome in healthcare workers [1], and it has become a sophisticated social issue and a sign of karoshi (death by overwork) for exhausted physicians, especially in China [2]. The prevalence of burnout among physicians varied greatly in studies [3], the overall burnout prevalence ranging from $0 \%$ to $80.5 \%$ among studies using the Maslach Burnout Inventory (MBI) [4]. According to the survey conducted by the Statistical Information Center of the Ministry of Health in China in $2010,52.4 \%$ of healthcare professionals have job burnout, of which $3.1 \%$ have a high degree. A greater 
level of burnout was correlated with sickness absence, more medical errors, poorer-quality healthcare and reduced patient safety [1,5-7]. For healthcare professionals, long-term job-related burnout may also lead to behavioral and psychiatric disorders and poor quality of life $[7,8]$.

It has been confirmed that the interaction of job demands and job decision latitude can lead to mental strain [9]. Conscientiousness, openness to experience and stress factors were factors that related to job burnout [10-12]. Studies using the MBI indicated that the job stress was strongly correlated with overall occupational burnout [13], and occupational stress was also positively associated with the three dimensionalities of job burnout, i.e., exhaustion, cynicism and professional efficacy [14].

In recent years, health alliances have been established throughout China as an important facilitator of a graded diagnosis and treatment system [15]. County-level health alliances refer to alliances comprised of a leading county-level hospital and several township clinics in close geographic proximity. The leading hospitals are responsible for business guidance, personnel training, reasonable allocation of funds from the New Rural Cooperative Medical Scheme to the members and provision of primary medical and health services for demanders. Health alliances could improve the quality of primary care in some aspects by helping to shift the high-quality health resources from tertiary and secondary hospitals to the primary health facilities [16].

Qinghai Province is located in Northwestern China and mostly in the Tibetan Plateau, and the province has long been a multi-ethnic settlement. The number of health workers per thousand population in Qinghai Province was 8.17 in 2016, while the figure on county-level or primary hospitals was the lowest [17]. In a context of health care reform and a changing health care environment, medical staff need to address the new requirements of high-level professional skills and the provision of comprehensive health services, which could produce inevitable job stress and potential burnout.

Therefore, the aim of this study was to examine the degrees of job burnout and occupational stressors and their associations among healthcare professionals from county-level health alliances in Qinghai-Tibet Plateau areas, China. Based on the previous studies, we made the hypotheses that job burnout could be common among the participants and there could be associations between job burnout and some domains of occupational stressors.

\section{Materials and Methods}

\subsection{Study Design and Data Collection}

This cross-sectional study was carried out in the capital city of Qinghai Province of China, i.e., Xining, in November 2018. Healthcare professionals from four county-level health alliances (2 general health alliances and 2 Chinese traditional health alliances) in Minhe county and Ledu district were invited to participate in this survey. All four leading county-level hospitals in those two counties were included in this study. Township health center was selected by a random sampling method, 18 township health centers were finally included, and the cluster-sampling method was used to recruit participants in each hospital and township health center. Temporary or visiting staff was excluded from this study.

The formula of the sample size calculation is $N=\frac{Z_{a}^{2} \times P(1-P)}{d^{2}}$ [18]. According to one review, the prevalence of job burnout among Chinese doctors is $66.5-87.8 \%$ [19], and we estimated the percentage of loss to follow-up to be $20 \%$, which reflects a response rate of $80 \%$. The sample size should be a minimum of 242 using the prevalence of $66.5 \%$.

Pre-established electronic questionnaires with a link were sent to healthcare professionals' WeChat (a Chinese multi-purpose messaging, social media and mobile payment app) working group by administrative staff from the medical department of each hospital; participants returned the questionnaire after completion. The process followed the principle of anonymity and voluntariness. All the healthcare professionals involved in this survey signed the informed consent form. The study protocol was approved by the ethics committee of the Medical College, Qinghai University 
(QHMC-2018-00037-PH). The report of this study was in accordance with the Strengthening the Reporting of Observational Studies in Epidemiology (STROBE) guidelines [20].

\subsection{Assessment}

The questionnaire used in this study consisted of three parts: basic social-demographic characteristics; the Maslach Burnout Inventory-General Survey (MBI-GS); and Chinese version of the Scale for occupational stressors on clinicians.

\subsubsection{Basic Social-Demographic Characteristics}

Basic social-demographic and working characteristics with regard to sex, marital status, professional group, department, working years, hospital level and hospital category were collected.

\subsubsection{Measurement of Burnout}

The Maslach Burnout Inventory-General Survey (MBI-GS) (Cronbach's alpha: 0.818) was used to evaluate job burnout among healthcare professionals [21,22]. The Chinese version has been validated and widely used [23]. The scale consists of three dimensions: emotional exhaustion (EE), cynicism (CY) and reduced professional efficacy (PE). The response of each item is a 7-point Likert scale ranging from $0=$ never to $6=$ daily, indicating the frequency of experiencing each symptom. All items in the dimension of reduced personal efficacy were reverse-coded. The score was weighted by the following formula to express the level of burnout [24]:

Total score $=0.4 \times$ emotional exhaustion $+0.3 \times$ cynicism $+0.3 \times$ reduced personal efficacy.

Higher scores indicated a higher level of job burnout. In this study, the level of burnout was classified into 3 categories: no burnout (scores 0-1.49), some burnout symptoms (moderate burnout hereafter) (scores 1.50-3.49) and serious burnout (3.50-6) [24].

\subsubsection{Occupational Stressors}

The 38-item Chinese version of the Scale for occupational stressors on clinicians with satisfactory psychometric properties (Cronbach's alpha: 0.879) [25] was used to assess the occupational stressors in this study. It is a 4-point Likert, which has been widely used in Chinese studies [26,27]. This scale is composed of seven domains: organization and management (8 items), vocational interest (8 items), work load (6 items), career development ( 7 items), interpersonal relationship ( 3 items), external environment ( 3 items) and doctor-patient relationship ( 3 items). Each item ranges from " 1 (very inconsistent)" to " 4 (very consistent)". Reverse scoring was adopted for the first seven items of vocational interest to avoid deviation caused by participants' inertial thinking, and higher scores indicate greater levels of stress [25]. The total score is the sum of the scores of each item, and the score for each domain is the sum score of its each item. The whole scale and details of items for each domain are shown in Supplementary Materials Tables S1 and S2.

\subsection{Statistical Analysis}

Description analyses were expressed using frequency, mean and standard deviation (SD) accordingly. The normal distribution of continuous variables was tested using the Shapiro-Wilk test. The Chi square test, $t$ test, analysis of variance (ANOVA) and Kruskal-Wallis H test were conducted appropriately as the univariate analyses. Multinomial logistic regressions were then preformed to identify the associations between job burnout $(\mathrm{Y})$ and occupational stressors as well as each domain by adjusting variables with significant difference in the univariate analysis. In each model, job burnout was set as the dependent variable, total score of occupational stressors and its each domain were separately set as the independent variables. The data were analyzed using SPSS, version 22.0 (SPSS Inc., Chicago, IL, USA) and the significance level was set at 0.05 (two-tailed). 


\section{Results}

\subsection{Basic Characteristics of the Participants}

A total of 1129 questionnaires were distributed and 1052 were collected giving a response rate of $93.2 \%$. The participants were from four leading county-level hospitals and 18 township health centers. The average age of the included healthcare professionals was $34.06(\mathrm{SD}=9.22)$ years, and $68.2 \%$ (717/1052, 95\% CI: 65.2-71.0\%) of the participants had moderate or serious degrees of job burnout. Table 1 shows the sociodemographic and working characteristics of healthcare professionals regarding different degrees of occupational burnout.

Table 1. Basic characteristics of the included participants.

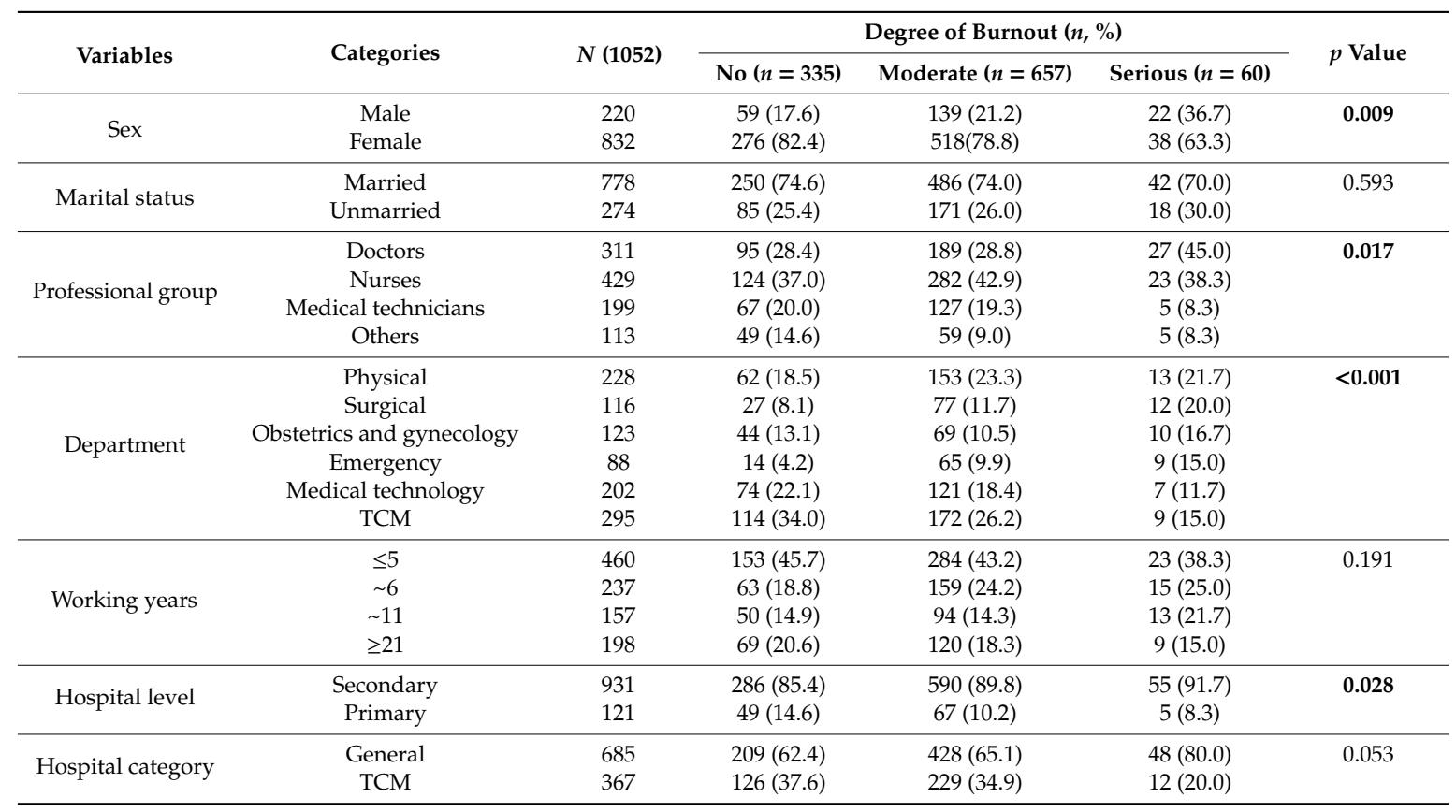

Bold values: $p<0.05$. TCM: Traditional Chinese medicine.

\subsection{Occupational Stressors at Different Degrees of Burnout}

The levels of occupational stressors at different degrees of burnout are shown in Table 2. The overall stressors score was $95.99 \pm 18.15$, and the scores for participants without burnout, with moderate and serious degree of burnout were $84.97 \pm 17.26,99.49 \pm 14.93$ and $119.25 \pm 18.13$, respectively. The Shapiro-Wilk test showed the total score of occupational stressor was not normally distributed as well as the score on the domains of organization and management, career development, interpersonal relationship and doctor-patient relationship, Kruskal-Wallis tests were conducted as the univariate analysis for them. Significant differences were found on the three degrees of burnout in all seven domains and overall score of occupational stressors $(p<0.001)$. 
Table 2. Score of occupational stressors at different degrees of burnout among healthcare professionals.

\begin{tabular}{|c|c|c|c|c|c|}
\hline \multirow{2}{*}{ Occupational Stressors $(\mathbf{M} \pm \mathrm{SD})$} & \multirow{2}{*}{$\begin{array}{c}\text { Total } \\
(N=1052)\end{array}$} & \multicolumn{3}{|c|}{ Degree of Burnout } & \multirow{2}{*}{$p$ Value } \\
\hline & & $\begin{array}{c}\text { No } \\
(n=335)\end{array}$ & $\begin{array}{l}\text { Moderate } \\
(n=657)\end{array}$ & $\begin{array}{l}\text { Serious } \\
(n=60)\end{array}$ & \\
\hline Organization and management * & $19.61 \pm 5.26$ & $17.49 \pm 5.55$ & $20.27 \pm 4.65$ & $24.33 \pm 5.26$ & $<0.001$ \\
\hline Vocational interest $\#$ & $17.59 \pm 5.29$ & $13.81 \pm 4.40$ & $18.85 \pm 4.35$ & $24.83 \pm 5.05$ & $<0.001$ \\
\hline Workload $\#$ & $17.23 \pm 4.11$ & $16.03 \pm 4.24$ & $17.54 \pm 3.83$ & $20.48 \pm 4.01$ & $<0.001$ \\
\hline Career development * & $17.79 \pm 4.96$ & $15.65 \pm 5.15$ & $18.50 \pm 4.35$ & $22.10 \pm 5.17$ & $<0.001$ \\
\hline Interpersonal relationship * & $5.42 \pm 2.13$ & $4.59 \pm 1.96$ & $5.75 \pm 2.02$ & $6.48 \pm 2.72$ & $<0.001$ \\
\hline External environment ${ }^{\#}$ & $9.49 \pm 2.16$ & $9.16 \pm 2.14$ & $9.56 \pm 2.12$ & $10.62 \pm 2.28$ & $<0.001$ \\
\hline Doctor-patient relationship * & $8.86 \pm 2.32$ & $8.24 \pm 2.51$ & $9.03 \pm 2.14$ & $10.40 \pm 2.12$ & $<0.001$ \\
\hline Total score * & $95.99 \pm 18.15$ & $84.97 \pm 17.26$ & $99.49 \pm 14.93$ & $119.25 \pm 18.13$ & $<0.001$ \\
\hline
\end{tabular}

${ }^{\#}$ Analysis of variance (ANOVA); * Kruskal-Wallis test.

\subsection{Associations between Occupational Stressors and Burnout}

Multinomial logistic regression models showed that after adjusting the variables with statistical significance in univariate analyses, the total score of occupational stressors and every domain were respectively and positively associated with moderate and serious level of burnout. The odds ratios of total occupational stressors for moderate burnout and serious level of burnout were 1.06 (95\% CI: 1.05-1.07) and 1.15 (95\% CI: 1.13-1.19), respectively. Occupational stressors from vocational interest (OR $=1.76,95 \%$ CI: $1.62-1.92)$, doctor-patient relationship (OR $=1.58,95 \%$ CI: $1.35-1.85)$ and interpersonal relationship ( $\mathrm{OR}=1.54,95 \% \mathrm{CI}$ : 1.35-1.76) showed the highest magnitude of odds ratio to serious level of burnout. Stressors from interpersonal relationship (OR $=1.35,95 \%$ CI: 1.25-1.45) and vocational interest $(\mathrm{OR}=1.30,95 \% \mathrm{CI}$ : $1.25-1.35)$ showed the highest magnitude of odds ratio to moderate level of burnout (Table 3).

Table 3. The associations between different domains of occupational stressors and burnout.

\begin{tabular}{ccc}
\hline \multirow{2}{*}{ Occupational Stressors } & Moderate Burnout & Serious Burnout \\
\cline { 2 - 3 } & OR (95\% CI) & OR (95\% CI) \\
\hline Organization and management & $1.11(1.08,1.14)^{* * *}$ & $1.30(1.22,1.38)^{* * *}$ \\
Vocational interest & $1.30(1.25,1.35)^{* * *}$ & $1.76(1.62,1.92)^{* * *}$ \\
Workload & $1.09(1.06,1.13)^{* * *}$ & $1.34(1.22,1.47)^{* * *}$ \\
Career development & $1.13(1.10,1.17)^{* * *}$ & $1.34(1.25,1.44)^{* * *}$ \\
Interpersonal relationship & $1.35(1.25,1.45)^{* * *}$ & $1.54(1.35,1.76)^{* * *}$ \\
External environment & $1.08(1.01,1.15)^{*}$ & $1.42(1.19,1.68)^{* * *}$ \\
Doctor-patient relationship & $1.15(1.08,1.21)^{* * *}$ & $1.58(1.35,1.85)^{* * *}$ \\
Total score & $1.06(1.05,1.07)^{* * *}$ & $1.15(1.13,1.19)^{* * *}$
\end{tabular}

Note: Multinomial logistic regression models by adjusting for sex, professional group, department, hospital level. Dependent variable: burnout; independent variable in each model: total score of each domain of occupational stressor and the total score, separately. OR: odds ratio, by setting participants without burnout as the reference group. CI: Confidence interval. ${ }^{*} p<0.05 ;{ }^{* * *} p<0.001$.

\section{Discussion}

This is the first study examining the degree of job burnout, occupational stressors and their relationship among healthcare professionals from county-level health alliances in Qinghai-Tibet Plateau areas, China. The prevalence of moderate and serious degrees of job-related burnout was $68.2 \%$ among our participants. There were positive associations between occupational stressors and job burnout, and vocational interest showed the highest magnitude of odds ratio to serious level of job burnout among the seven domains of occupational stressors, followed by doctor-patient relationship, interpersonal relationship and other domains.

The prevalence of job-related burnout was higher than the figure of $56.6 \%$ found in one Chinese study among obstetricians and pediatricians working in provincial hospitals [28], while it was lower than the $76.9 \%$ in another Chinese study including physicians from 10 provinces in China [29]. 
Compared to other countries, our figure was also significantly higher than that among French physicians (49\%, 95\% CI: 45-53\%) [30] and Iranian nurses (36\%, 95\% CI: 20-53\%) [31], and greater than the health professionals in Ecuador (2.6\%) [32] and physicians in USA (56.6\%) [33]. Inconsistencies on the definition of burnout and assessment tools, etc., could partly explain the disparities between studies [4]. Besides, cultural, regional and economic factors in different countries could have a role; for example, lower annual income was reported to be associated with higher level of burnout [34].

This study was conducted among the county-level health alliances, in which the secondary hospital is the leading hospital and the primary hospital is its subordinate. Under the assistance and management of the leading hospital, primary hospitals are mainly responsible for providing healthcare services to the local residents, which means that professionals who work in the primary hospitals would have to enhance their knowledge and acquire more advanced medical techniques to meet the demands for health services [35], which could partly increase their occupational stress and job burnout.

Occupational stressors were positively associated with both moderate and serious degrees of job burnout, which have been identified in previous studies [36,37]. It has been reported that occupational stressors make the greatest contribution to nurses' job burnout compared with socio-demographic characteristics [38]. The participants in this study were from county-level health alliances in Qinghai Province, China, which has a relatively lagging economy (compared to some other Provinces in China) and a sparsely distributed population. In 2014, the number of health technicians and practicing (and assistant) physicians per thousand population in Qinghai Province was highest in the capital city, Xining ( 9.69 vs. 3.44), and lowest in Haidong city ( 2.65 vs. 0.93) [39]. The implementation and development of the health alliances is a key to deepening the health reform in China. There are still deficiencies in the allocation of primary health care personnel, such as unbalanced distribution and loss of personnel, which could partly result in the extension of working hours and stress of primary healthcare professionals as well as their job burnout.

Vocational interest produced odds ratio of the greatest magnitude to serious job burnout, followed by doctor-patient relationship, interpersonal relationship and other domains of occupational stressors. People will achieve better job performance and obtain a longer term job satisfaction if their interests match their careers [40], and job performance has been frequently reported to have a negative relationship with job burnout [41,42]. The potential mediating role of job performance could also partly explain the strong association between vocational interest and job burnout. China has witnessed a surge in medical disputes in recent years, the detrimental influences of the damaged doctor-patient relationship irresistibly emerged [43]. Besides, the high prevalence of workplace violence from patients and their family or their co-workers has been frequently reported among Chinese healthcare professionals [44], which could also explain the associations between interpersonal relationship and doctor-patient relationship. Stressors from career development and workload also played roles in the high level of burnout. The structural imbalance of healthcare professional titles is prominent in China, and there were great urban-rural and regional gaps [45], which were serious in Qinghai Province. It is difficult for many clinicians, especially young doctors, to be promoted under the current promotion systems, which could definitely influence clinicians' enthusiasm and lead to psychological disorders. Heavy workload of hospital workers is also a major problem for the Chinese health care system [29].

Healthcare professionals with high burnout were at a greater risk of suffering from poor physical, cognitive and emotional well-being [37,46]. Improving the quality of primary care, physical and mental health of health care providers should also be of concern. It has been identified that both individual-focused and structural or organizational strategies can bring about clinically meaningful reductions in physicians' burnout [47], especially adoption of organization-directed approaches [48]. Therefore, effective measures to reduce job burnout among medical staff, in particular those measures based on health care organization, should be considered.

There were some limitations in this study. First, information such as personal economic status, family support and information on the hospitals in which the respondent works, etc., which could be 
confounding factors were not collected. Second, only healthcare professionals working in county-level health alliances in Qinghai Province were included; participants from multiple provinces should be recruited in future research. In addition, the existing literatures using the Chinese version of the Scale for occupational stressors on clinicians were only published in Chinese, which limited the possible comparisons among studies for international readerships. Lastly, the causal relationship between occupational stressors and job burnout cannot be generated due to the cross-sectional design; thus, further longitudinal studies are warranted.

\section{Conclusions}

In conclusion, job burnout was very common among the healthcare professionals working in the Chinese county-level health alliances. Occupational stressors had positive associations with moderate and serious levels of job burnout. Effective policies and measures should be appropriately developed and implemented at the national, regional or institutional level, accordingly, to alleviate the level of work pressure and job burnout and ensure psychological health of health service providers in Chinese county-level health alliances.

Supplementary Materials: The following are available online at http://www.mdpi.com/1660-4601/17/6/1848/s1, Table S1: The Chinese version of Scale for occupational stressors on clinicians, Table S2: Details of items in each domain in the Scale for occupational stressors on clinicians.

Author Contributions: Y.L., C.-C.W. and L.L. designed the study. Y.L., W.-X.W., S.L., H.-R.C., X.G., M.-Y.H., Y.-M.R. and Y.-N.L. conducted the data collection. Y.L., L.L., W.-X.W. and C.-C.W. analyzed and interpreted the data. Y.L. and L.L. drafted the manuscript. Y.L., L.L. and C.-C.W. critically revised the manuscript. All authors have read and agreed to the published version of the manuscript.

Funding: This study was supported by the Qinghai University Scientific Research Project of Young Teachers in Qinghai University (NO2018-QSY-7).

Acknowledgments: This survey was conducted by the research team from the Medical College of Qinghai University in collaboration. We thank Hui-Min Ren from Minhe County Health and Health Committee and Xiao-Qing Zhu from the Ledu district Health and Health Committee for their great help in the data collection.

Conflicts of Interest: The authors declare that they have no competing interests.

\section{References}

1. Romani, M.; Ashkar, K. Burnout among physicians. Libyan J. Med. 2014, 9, 23556. [CrossRef] [PubMed]

2. Yang, C.; Chen, Z.L.; Chen, L.Y.; Jiang, J.X. Burnout in healthcare: A sign of death by overwork for doctors in China. BMJ 2019, 366, 15582. [CrossRef] [PubMed]

3. van Mol, M.M.; Kompanje, E.J.; Benoit, D.D.; Bakker, J.; Nijkamp, M.D. The Prevalence of Compassion Fatigue and Burnout among Healthcare Professionals in Intensive Care Units: A Systematic Review. PLoS ONE 2015, 10, e0136955. [CrossRef] [PubMed]

4. Rotenstein, L.S.; Torre, M.; Ramos, M.A.; Rosales, R.C.; Guille, C.; Sen, S.; Mata, D.A. Prevalence of Burnout Among Physicians: A Systematic Review. JAMA 2018, 320, 1131-1150. [CrossRef]

5. Salyers, M.P.; Bonfils, K.A.; Luther, L.; Firmin, R.L.; White, D.A.; Adams, E.L.; Rollins, A.L. The Relationship Between Professional Burnout and Quality and Safety in Healthcare: A Meta-Analysis. J. Gen. Intern. Med. 2017, 32, 475-482. [CrossRef]

6. Liu, X.; Zheng, J.; Liu, K.; Baggs, J.G.; Liu, J.; Wu, Y.; You, L. Hospital nursing organizational factors, nursing care left undone, and nurse burnout as predictors of patient safety: A structural equation modeling analysis. Int. J. Nurs. Stud. 2018, 86, 82-89. [CrossRef]

7. Anagnostopoulos, F.; Niakas, D. Job Burnout, Health-Related Quality of Life, and Sickness Absence in Greek Health Professionals. Eur. Psychol. 2010, 15, 132-141. [CrossRef]

8. Yao, Y.; Zhao, S.; Zhang, Y.; Tang, L.; An, Z.; Lu, L.; Yao, S. Job-related burnout is associated with brain neurotransmitter levels in Chinese medical workers: A cross-sectional study. J. Int. Med. Res. 2018, 46, 3226-3235. [CrossRef]

9. Karasek, R.A., Jr. Job demands, job decision latitude, and mental strain: Implications for job redesign. Adm. Sci. Q. 1979, 24, 285-308. [CrossRef] 
10. Pérez-Fuentes, M.D.C.; Molero Jurado, M.D.M.; Martos Martínez, Á.; Gázquez Linares, J.J. Analysis of the risk and protective roles of work-related and individual variables in burnout syndrome in nurses. Sustainability 2019, 11, 5745. [CrossRef]

11. Perez-Fuentes, M.D.C.; Molero Jurado, M.D.M.; Martos Martinez, A.; Gazquez Linares, J.J. Burnout and Engagement: Personality Profiles in Nursing Professionals. J. Clin. Med. 2019, 8, 286. [CrossRef] [PubMed]

12. Van der Heijden, B.; Brown Mahoney, C.; Xu, Y. Impact of Job Demands and Resources on Nurses' Burnout and Occupational Turnover Intention Towards an Age-Moderated Mediation Model for the Nursing Profession. Int. J. Environ. Res. Public Health 2019, 16, 2011. [CrossRef] [PubMed]

13. Hsu, H.Y.; Chen, S.H.; Yu, H.Y.; Lou, J.H. Job stress, achievement motivation and occupational burnout among male nurses. J. Adv. Nurs. 2010, 66, 1592-1601. [CrossRef] [PubMed]

14. Wu, S.; Zhu, W.; Wang, Z.; Wang, M.; Lan, Y. Relationship between burnout and occupational stress among nurses in China. J. Adv. Nurs. 2007, 59, 233-239. [CrossRef]

15. Xin, Q.L.; Min, S.; Fang, P.Q.; Tang, C.M. Key issues and pathway of the incentive and constraint mechanism of medical alliances in China (in Chinese). Chin. J. Hosp. Adm. 2017, 33, 889-892.

16. Su, M.; Zhou, Z.L.; Si, Y.F.; Wei, X.L. Effect of health alliances on the quality of primary care in urban China: A coarsened exact matching difference-in-differences analysis. Lancet 2019, 394, S86. [CrossRef]

17. The Qinghai Province Health\&Family Planning Commission. Qinghai Health and Family Planning Statistics Yearbook 2017; The Qinghai Province Health Information Center: Qinghai, China, 2017.

18. Kramer, M.S. Clinical Epidemiology and Biostatistics, 1st ed.; Springer: Berlin, Germany, 1988; Volume 157.

19. Lo, D.; Wu, F.; Chan, M.; Chu, R.; Li, D. A systematic review of burnout among doctors in China: A cultural perspective. Asia Pac. Fam. Med. 2018, 17, 3. [CrossRef]

20. Von Elm, E.; Altman, D.G.; Egger, M.; Pocock, S.J.; Gotzsche, P.C.; Vandenbroucke, J.P.; Initiative, S. The Strengthening the Reporting of Observational Studies in Epidemiology (STROBE) statement: Guidelines for reporting observational studies. Prev. Med. 2007, 45, 247-251. [CrossRef]

21. Maslach, C.; Jackson, S.E. The measurement of experienced burnout. J. Organ. Behav. 1981, 2, 99-113. [CrossRef]

22. Schaufeli, W.B. Maslach Burnout Inventory-General Survey (MBIGS). In Maslach Burnout Inventory Manual; Mindgarden: California, CA, USA, 1996.

23. Li, C.P.; Shi, K. The influence of distributive justice and procedural justice on job burnout. Acta Psychol. Sin. 2003, 35, 677-684. (In Chinese)

24. Kalimo, R.; Pahkin, K.; Mutanen, P.; Topipinen-Tanner, S. Staying well or burning out at work: Work characteristics and personal resources as long-term predictors. Work Stress 2003, 17, 109-122. [CrossRef]

25. Chen, J.P. Compilation and Application of the Scale for Occupational Stressors on Clinician; Shanghai Normal University: Shanghai, China, 2009. (In Chinese)

26. Chen, F.P.; Yin, Y.M.; Li, Y.; Lin, B.L.; Yang, R.Q.; Du, M.R. Analysis of occupational stress and doctor-patient relationship among neurologists. Occup. Health Emerg. Res. 2019, 37, 234-237. (In Chinese)

27. Zhang, Y.; Wang, S.X.; Sun, H.W.; Wang, H. Occupational stress of clinicians in a 3A Grade hospital in Xinjiang and its relationship with depression and hypertension. J. Int. Psychiatry 2018, 45, 81-83. (In Chinese)

28. Ye, J.; Wang, H.; Wu, H.; Ye, L.; Li, Q.; Ma, X.Y.; Yu, X.; Zhang, H.; Luo, X. Burnout among obstetricians and paediatricians: A cross-sectional study from China. BMJ Open 2019, 9, e024205. [CrossRef] [PubMed]

29. Wen, J.; Cheng, Y.; Hu, X.; Yuan, P.; Hao, T.; Shi, Y. Workload, burnout, and medical mistakes among physicians in China: A cross-sectional study. BioSci. Trends 2016, 10, 27-33. [CrossRef] [PubMed]

30. Kansoun, Z.; Boyer, L.; Hodgkinson, M.; Villes, V.; Lancon, C.; Fond, G. Burnout in French physicians: A systematic review and meta-analysis. J. Affect. Disord. 2019, 246, 132-147. [CrossRef]

31. Rezaei, S.; Karami Matin, B.; Hajizadeh, M.; Soroush, A.; Nouri, B. Prevalence of burnout among nurses in Iran: A systematic review and meta-analysis. Int. Nurs. Rev. 2018, 65, 361-369. [CrossRef]

32. Ramirez, M.R.; Otero, P.; Blanco, V.; Ontaneda, M.P.; Diaz, O.; Vazquez, F.L. Prevalence and correlates of burnout in health professionals in Ecuador. Compr. Psychiatry 2018, 82, 73-83. [CrossRef]

33. Olson, K.; Sinsky, C.; Rinne, S.T.; Long, T.; Vender, R.; Mukherjee, S.; Bennick, M.; Linzer, M. Cross-sectional survey of workplace stressors associated with physician burnout measured by the Mini-Z and the Maslach Burnout Inventory. Stress Health 2019, 35, 157-175. [CrossRef]

34. Yang, S.; Meredith, P.; Khan, A. Stress and burnout among healthcare professionals working in a mental health setting in Singapore. Asian J. Psychiatry 2015, 15, 15-20. [CrossRef] 
35. Zhou, G.L.; Chen, J.Y.; Miao, Y.D.; Hu, D. Study on work pressure of grassroots medical staff in jiangsu province. J. Nanjing Med. Univ. 2008, 18, 349-352.

36. Barnard, D.; Street, A.; Love, A.W. Relationships between stressors, work supports, and burnout among cancer nurses. Cancer Nurs. 2006, 29, 338-345. [CrossRef] [PubMed]

37. Privitera, M.R.; Rosenstein, A.H.; Plessow, F.; LoCastro, T.M. Physician burnout and occupational stress: An inconvenient truth with unintended consequences. J. Hosp. Adm. 2015, 4, 27-35. [CrossRef]

38. Mirzaei, R.; Hafezi-Nejad, N.; Sadegh Sabagh, M.; Ansari Moghaddam, A.; Eslami, V.; Rakhshani, F.; Rahimi-Movaghar, V. Dominant role of drivers' attitude in prevention of road traffic crashes: A study on knowledge, attitude, and practice of drivers in Iran. Accid. Anal. Prev. 2014, 66, 36-42. [CrossRef] [PubMed]

39. Gou, L.J. A Study on Status and Equity of Allocation of Health Resources in Qinghai Province; Lanzhou University: Lanzhou, China, 2016. (In Chinese)

40. Holland, J.L.; Gottfredson, G.D.; Baker, H.G. Validity of vocational aspirations and interest inventories: Extended, replicated, and reinterpreted. J. Couns. Psychol. 1990, 37, 337. [CrossRef]

41. Renzi, C.; Tabolli, S.; Ianni, A.; Di Pietro, C.; Puddu, P. Burnout and job satisfaction comparing healthcare staff of a dermatological hospital and a general hospital. J. Eur. Acad. Dermatol. Venereol. 2005, 19, 153-157. [CrossRef]

42. Kalliath, T.; Morris, R. Job satisfaction among nurses: A predictor of burnout levels. J. Nurs. Adm. 2002, 32, 648-654. [CrossRef]

43. He, A.J.; Qian, J. Explaining medical disputes in Chinese public hospitals: The doctor-patient relationship and its implications for health policy reforms. Health Econ. Policy Law 2016, 11, 359-378. [CrossRef]

44. Lu, L.; Dong, M.; Wang, S.B.; Zhang, L.; Ng, C.H.; Ungvari, G.S.; Li, J.; Xiang, Y.T. Prevalence of Workplace Violence Against Health-Care Professionals in China: A Comprehensive Meta-Analysis of Observational Surveys. Trauma Violence Abuse 2018. [CrossRef]

45. Zhu, X.L.; Chen, Q.K.; Yang, S.X. The current situation and problems of primary health care personnel since the new round of China's health care reform. Chin. J. Health Policy 2015, 8, 57-62. (In Chinese)

46. Asante, J.O.; Li, M.J.; Liao, J.; Huang, Y.X.; Hao, Y.T. The relationship between psychosocial risk factors, burnout and quality of life among primary healthcare workers in rural Guangdong province: A cross-sectional study. BMC Health Serv. Res. 2019, 19, 447. [CrossRef] [PubMed]

47. West, C.P.; Dyrbye, L.N.; Erwin, P.J.; Shanafelt, T.D. Interventions to prevent and reduce physician burnout: A systematic review and meta-analysis. Lancet 2016, 388, 2272-2281. [CrossRef]

48. Panagioti, M.; Panagopoulou, E.; Bower, P.; Lewith, G.; Kontopantelis, E.; Chew-Graham, C.; Dawson, S.; van Marwijk, H.; Geraghty, K.; Esmail, A. Controlled Interventions to Reduce Burnout in Physicians: A Systematic Review and Meta-analysis. JAMA Intern. Med. 2017, 177, 195-205. [CrossRef] [PubMed] 